\title{
A INCOMPLETUDE NARRATIVA COMO EFEITO DE SENTIDO NOS JOGOS DIGITAIS
}

\author{
Renato Razzino Ernica*
}

\begin{abstract}
RESUMO: Se tomarmos o termo "narrativa" em um sentido amplo, certamente não poderíamos atestar que todo e qualquer jogo digital constitua uma narrativa. Tetris, por exemplo, apresenta blocos que precisam ser encaixados em linhas para gerar pontos, não constituindo uma narrativa per se. Já em Donkey Kong as relações entre figuras como um homem, um gorila e uma princesa abalam um estado prévio de coisas e tecem uma narrativa com começo, meio e fim. Apesar disso, Jesper Juul (2005) caracteriza esse tipo de universo ficcional como incompleto - não sabemos de onde vem a princesa, como o gorila a capturou -, e incoerente - a personagem principal tem várias vidas disponíveis. Essa postura crítica é problemática, em nossa opinião, pois: 1) considera o jogo como um meio de retratar um universo pré-existente, na medida em que, para ser incompleto, é preciso haver uma completude além da que se mostra no jogo e independente dele; e 2) aplica como medidor de coerência elementos alheios ao gênero "jogo digital", como os da "vida real" ou de demais artes. Nossa proposta é de que os elementos problemáticos para Juul são constitutivos da forma expressiva em si, e portanto não podem torná-la incoerente nem incompleta - sendo a incompletude um efeito de sentido gerado pelo modo próprio desse meio expressivo conjugar-se a um conteúdo seja ele qual for e também um meio de ampliar a própria experiência ficcional. Para embasar as afirmações aqui presentes utilizaremos os trabalhos de Aristóteles, Achcar (1994) e Murray (1997).
\end{abstract}

PALAVRAS-CHAVE: Semiótica Francesa. Teoria Narrativa. Jogos Digitais. Cibercultura.

\section{Introdução}

O termo "narrativa" representa um problema dentro das ciências humanas, pois tem, em diferentes campos, usos os mais diversos. Na acepção do Dicionário Houaiss da Língua Portuguesa, observa-se o seguinte:

\begin{abstract}
Narrativa s.f. (1623) 1 ação, processo ou efeito de narrar; narração 2 exposição de um acontecimento ou de uma série de acontecimentos mais ou menos encadeados, reais ou imaginários, por meio de palavras ou de imagens 3 conto, história, caso 4 o modo de narrar 5 LIT prosa literária (conto, novela, romance etc.), caracterizada pela presença personagens inseridos em situações imaginárias; ficção 6 LIT o conjunto das obras de determinado autor ou de uma determinada época, de um país etc. <a $n$. De José de Alencar > <a n. pós-moderna > <a n. italiana>. (HOUAISS; VILLAR, 2009, p. 1342)
\end{abstract}

\footnotetext{
* Faculdade de Filosofia, Letras e Ciências Humanas da Universidade de São Paulo, São Paulo, Brasil. Imeio: renatorazzino@hotmail.com
} 
A linha de sinônimos fornecida pelo dicionário é a mesma do verbete "exposição", ou seja, trata-se do ato de apresentar, mas não de qualquer maneira um caso: é preciso que os acontecimentos sejam "mais ou menos encadeados" e que sejam veiculados por meio de "palavras ou imagens" - uma sequência de sons aleatórios não constitui uma narrativa. Há, portanto, um princípio organizacional, seja ele qual for, que determina o que deve ser uma narrativa. Aristóteles, no capítulo VII de sua Poética, ao discorrer sobre a estrutura do mito trágico, diz o seguinte:

40. Assim determinados os elementos da tragédia [ação, caráter etc.], digamos agora qual deve ser a composição dos atos, pois é esta parte, na tragédia, a primeira e a mais importante.

41. Já ficou assente que a tragédia é imitação de uma ação completa, constituindo um todo que tem certa grandeza, porque pode haver um todo que não tenha grandeza.

42. "Todo" é aquilo que tem princípio, meio e fim. "Princípio" é o que não contém em si mesmo o que quer que siga necessariamente outra coisa, e que, pelo contrário, tem depois de si algo com que está ou estará necessariamente unido. "Fim", ao invés, é o que naturalmente sucede a outra coisa, por necessidade ou porque assim acontece na maioria dos casos, e que, depois de si, nada tem. "Meio" é o que está depois de alguma coisa e tem outra depois de si. (SOUSA, 1973, p. 247)

A reflexão aristotélica coloca a organização das partes do mito - o equivalente ao que chamaríamos de "enredo", ou seja, o que se passa na tragédia, tendo em vista que, para Aristóteles, a imitação trágica é sempre de ações - em unidades interdependentes como a chave para o sucesso da tragédia - lembrando que o objetivo do texto é discorrer acerca dos elementos de uma boa tragédia, não de tragédias quaisquer. Essa organização, como se pode ver no trecho citado logo acima, diz respeito não necessariamente a uma ordem de colocação no texto, mas a uma ligação lógica entre as partes: o princípio causa o meio que causa o fim, seja "por necessidade ou porque assim acontece na maioria dos casos". Estamos, portanto, diante de um conceito cuja base se forma na causalidade.

Além da causalidade, Aristóteles aponta para a questão da extensão: trata-se de uma ação completa, de certa grandeza e que precisa ser passível de apreensão no tempo determinado em que decorre o evento: 
44. Além disto, o belo - ser vivente ou o que quer que se componha de partes - não só deve ter essas partes ordenadas, mas também uma grandeza que não seja qualquer. Porque o belo consiste na grandeza e na ordem, e portanto um organismo vivente, pequeníssimo, não poderia ser belo (pois a visão é confusa quando se olha por tempo quase imperceptível); e também não seria belo, grandíssimo (porque faltaria a visão do conjunto, escapando à vista dos espectadores a unidade e a totalidade; imagine-se, por exemplo, um animal de dez mil estádios...). Pelo que, tal como os corpos e organismos viventes devem possuir uma grandeza, e esta bem perceptível como um todo, assim também os mitos devem ter uma extensão bem apreensível pela memória. (Idem, p. 247248)

A questão da memória é essencial para a noção de causalidade, já que é preciso, no fim, que se tenha uma visão do início. Tanto a falta de detalhes quanto seu excesso são indesejáveis, sendo necessário ver o que é de fato relevante e imprescindível mostrar, e nem todas as informações requeridas para a compreensão do que quer que seja precisam estar necessariamente colocadas na ação em si, mas podem ser retomadas, ou até mantidas latentes, nas ditas entrelinhas que jogam com o que se subentende. A questão do início ab ovo, como ficou conhecido a partir do texto da Poética, é primordial para toda a construção de narrativa: onde se encontra o início do caso? Até que ponto podese afirmar, quanto a um acontecimento qualquer, que se trata de algo cuja causalidade não é determinada previamente por necessidade, mas que com certeza gerou consequências? O trabalho de composição narrativa é, portanto, de seleção e recombinação de elementos de modo a atingir um produto em que seja possível reconhecer uma linha causal, a qual é construída e inexiste a priori da seleção. Sendo uma causalidade forjada, qualquer peça narrativa, seja ela referente a um caso da ordem do real ou puramente do universo da imaginação, será obrigatoriamente ficcional - fictio, derivada do verbo latino fingere, do qual retiramos "fingir" e que tem o sentido de "forjar".

Ainda em Aristóteles, viu-se que a união das diversas partes que formam o mito é denominado como "todo" e que há determinada grandeza relativa a ele. Isso nos dá base para aprofundar a reflexão: sendo o todo o conjunto de partes ligadas por uma ordem lógica, a qual existe apenas enquanto derivada de um ponto de vista, podemos pressupor que todo "todo" é, em si, uma parte, levando-se em conta que 
nosso ponto de vista jamais consegue abranger uma totalidade absoluta e, no caso de uma narrativa, isso seria indesejável caso os preceitos aristotélicos fossem seguidos. Isso garante que cada história possa ser considerada apenas parte de algo maior, como cada história da Grécia Antiga corresponde a apenas uma dentre diversas que compõem o quadro mais geral do que chamamos Mitologia Grega.

Seguindo uma lógica parecida com a descrita acima, Juul (2005), ao estudar as relações entre ficção e regras dentro de um jogo (opostas por ele em seu trabalho), descreve os universos ficcionais presentes nos jogos digitais como incompletos, pois há uma grande quantidade de informação a que não podemos ter acesso direto e que, portanto, precisamos imaginar:

\begin{abstract}
In fictional worlds, there is an important distinction between the description of a fictional world and the fictional world as it is actually imagined. [...] Thus, the reader performs much work in order to imagine a fictional world, and consequently diferente readers and game players will imagine a fictional world differently. [...] This is because all fictional worlds are incomplete. No fiction exists that completely specifies all aspects of a fictional world. (Cap. 4$)^{1}$
\end{abstract}

O problema na visão de Juul reside na seguinte falha conceitual: para que um universo ficcional qualquer seja incompleto é preciso haver uma completude inatingida (ou inatingível) cuja existência seja independente do objeto, sendo este apenas um meio de representação. É como uma câmera cuja lente é capaz de captar somente uma parcela do que o olho apreende, e que sabemos estar lá. Porém, ao lidar com fotografia, reconhece-se que fatores como enquadramento, foco e iluminação a tornam um meio de criação, pois o direcionamento do olhar derivado dos fatores mencionados nos faz ver de outro modo, gerando possibilidades de sentido não existentes antes da intervenção do fotógrafo. Da mesma forma, um romancista, ao estruturar uma narrativa, faz uso dos mais diversos atributos da linguagem verbal (sonoridade, ritmo, estrutura morfológica, sintática, etc.) para criar situações as mais diversas, dar um "toque passional" ao

\footnotetext{
${ }^{1} \mathrm{O}$ texto foi lido na versão e-book, que não apresenta numeração de páginas. Não há normas da ABNT para citação de textos nesse formato, então foram seguidas as diretrizes internacionais e o capítulo onde o trecho se encontra está mencionado.
} 
texto e, inclusive, fazer com que o objeto não baste em si mesmo, atiçando a curiosidade do leitor para os elementos que ele decide calar. É a própria forma expressiva e seus mais variados atributos que, quando combinados de uma maneira e não de outra, criam o a sensação incompletude, indicando, portanto, que não se trata de objetos cujas limitações permitem-nos apenas retratar a parte e nunca o todo, mas sim de um efeito de sentido produzido por uma organização formal específica, por uma estética da incompletude, o que a descaracteriza, no fim das contas, como incompleta - é uma forma de expansão do perceptivo, não o contrário.

Juul ainda vai além em sua avaliação do modo como um universo ficcional se apresenta em forma de jogo. Segundo ele, o jogador muitas vezes se encontra diante de incoerências:

\begin{abstract}
In addition to incomplete worlds, some games, and many video games, presente game worlds that are incoherent worlds, where the game contradicts itself or prevents the player from imagining a complete fictional world. [...] The fictional world of Donkey Kong is only very superficially described, but it is possible to imagine a world in which Mario's girlfriend is kidnapped by an evil gorilla and has to be recued. [...] It is harder to understand why Mario has three lives: Being hit by a barrel, by a fireball, or by an anvil should reasonably be fatal. Furthermore, the player is rewarded with an extra Mario at 10,000 points. This is not a questiono d Donkey Kong being incomplete, but a question of the fictional world being incoherent or unimaginable. While, technically, any world can be imagined, and we could explain Mario's reappearance by appealing to magic or reincarnation, the point here is that nothing in Donkey Kong suggests a world where people magically come back to life after dying. In an informal survey of Donkey Kong players, all players explained the three lives by appealing to the rules of the game: With only one life, the game would be too hard. (Ibidem)
\end{abstract}

Basicamente, seguindo a lógica apontada pelo autor, qualquer jogo que apresente uma personagem envolvida em uma trama e que possibilite múltiplas tentativas ao jogador é incoerente, posto que o elemento de repetição do jogo impede o desenvolvimento fluido da linha narrativa presente naquele enredo específico: a história caminharia para um lado e as regras do jogo, para outro.

O mesmo problema de fundamento se repete nessa segunda consideração de Juul: ao separar os elementos formais do enredo, o autor adota a mesma postura 
descrita acima, que já se mostrou bastante controversa ${ }^{2}$. Como dito anteriormente, a perspectiva deste artigo baseia-se na noção de que um universo ficcional, seja ele qual for, é construído a partir dos elementos formais de determinado meio expressivo, o que elimina a possibilidade de incoerência no caso descrito por Juul, na medida em que os elementos considerados destoantes por ele são necessários para que um jogo seja reconhecido enquanto tal e é apenas por meio deles que a narrativa se torna possível - o que remete à antiga questão dos gêneros, bem trabalhada por Achcar (1994).

Dizendo de outro modo, o cinema faz sentido enquanto narrativa-em-filme, assim como o romance o faz enquanto narrativa-em-livro, pois cada meio expressivo tem suas idiossincrasias e a narrativa se faz a partir de sua (re)organização, sendo apenas por meio dela que pode ser apreendida e fazer sentido. Tendo em vista todos esses fatores, a apreciação dada por Juul à problemática do jogo digital nos parece inadequada, posto que o autor parece ignorar o fato de que um jogo não apresenta uma narrativa separada dos elementos formais que o caracterizam, mas sim cria a narrativa por meio deles. Diferente de um romance convencional, é comum que jogos trabalhem com outras bases narrativas, determinados por fatores como experiência do evento - em oposição a outras formas mais "contemplativas" de arte - e apresentação hipermidiática de conteúdo - que difere da linearidade do romance ou do filme. Essas características são essenciais para a estética do meio digital, como aponta Murray (1997) e devem ser estudadas em profundidade para que se entenda o que de fato está em jogo quando jogamos e não se analise, como faz Juul, o fenômeno que constitui o jogo digital com o mesmo instrumental moldado para atender às especificidades de outras formas expressivas - motivo pelo qual o autor considera seu objeto incoerente.

Tendo em vista que uma narrativa criada a partir de uma experiência de vídeo game não pode ser incoerente quando é justamente aquilo que se propõe a ser -

\footnotetext{
${ }^{2}$ Fica evidente que o autor não ignora a função prática das várias "vidas", mas separa as regras da produção ficcional, o que, como se pretende demonstrar, é uma postura inadequada.
} 
um jogo, o objetivo deste artigo é discutir algumas das especificidades dessa forma expressiva bastante recente no quadro das mais diversas artes, sobretudo no que diz respeito a fatores como experiência narrativa, saturação e sensação de universo expandido, que serão os tópicos trabalhados diretamente neste artigo. Vale a pena ressaltar que não se pretende aqui produzir um quadro teórico completo acerca do fenômeno dos jogos digitais, campo vasto de discussão que admite posicionamentos teóricos variados e igualmente válidos, ou então afirmar que os jogos digitais representam o fim de uma cadeia evolutiva na arte de narrar, superando formas "arcaicas" como a prosa de ficção ou o cinema; trata-se apenas de constatar que o objeto em foco é diferente dos demais e, portanto, não pode ser analisado com o mesmo instrumental sem que se chegue a conclusões depreciativas, ou por vezes equivocadas, acerca do objeto, como ocorre, por exemplo, com a crítica de Stallabrass (1996), a qual será discutida mais adiante.

\section{O jogo como narrativa participativa}

O primeiro passo para entender os mecanismos envolvidos na transposição de um enredo qualquer em forma de jogo é, justamente, definir o que é um jogo, sobretudo devido ao fato de existirem diversas manifestações narrativas nos dias atuais que fazem uso do meio digital e que envolvem participação, mas não podem ser consideradas jogos devido à ausência de uma mecânica específica, que não se confunde, em absoluto, com a estrutura de navegação em ambientes digitais.

Elementos como navegação em primeira pessoa, exploração livre de um cenário tridimensional e diversos outros estão, evidentemente, presentes em jogos digitais, mas não condizem com a mecânica de atividades como Pega-Pega, Peteca, Futebol ou Twister (Milton Bradley, 1966), todas elas bastante diferentes entre si, mas que, mesmo assim, são classificadas em um mesmo grupo: todas são jogos. Isso significa que o elemento definidor de um jogo não está nos elementos visuais e/ou sonoros per se, mas em uma estrutura que thes dê forma e que não está ligada a nenhum meio expressivo em particular. É justamente 
esse elemento que carece de definição clara e que é, ao fim e ao cabo, o alicerce da construção da narratividade e da elaboração de um enredo em um jogo.

Como ponto de partida, parece interessante contrastar a definição de Salen e Zimmerman (2004, parte 1), "A game is a system in which players engage in an artificial conflict, defined by rules, that results in a quantifiable outcome", com a de Juul:

\begin{abstract}
A game is a rule-based system with a variable and quantifiable outcome, where different outcomes are assigned different values, the player exerts effort in order to influence the outcome, the player feels emotionally attached to the outcome, and the consequences of the activity are negotiable. (Cap. 2)
\end{abstract}

A princípio, ambas parecem dizer a mesma coisa, na medida em que deixam claro que um jogo é um sistema baseado em regras com resultado quantificável. Além da quantificação, Juul acrescenta o atributo "variável", bem como as noções de "esforço" e "ligação emocional" ao resultado do jogo, o qual tem um "valor", que, se considerarmos a definição de Saussure, funciona por meio de oposição: algo é positivo em contraste com outro, negativo. O jogador se esforça para conseguir um resultado considerado bom, pois isso é agradável, enquanto tenta evitar um desfecho ruim, tendo em mente que, mesmo com múltiplas possibilidades, o contraste vai determinar seus valores - um empate é melhor que uma derrota, mas pior que uma vitória, por exemplo. Essa progressão lógica parece ser o que Salen e Zimmerman resumem por conflito, posto que uma das noções básicas do termo é justamente a de disputa de valores: um objeto-valor considerado positivo (no caso, a vitória) é colocado como meta e, a partir disso, o(s) jogador(es) irão engajar-se em uma atividade (artificial, como bem apontam os autores) para obtê-lo. A negociação das consequências é também importante, na medida em que jogos não costumam ser sérios ou ao menos não apresentam consequências fora do campo de atividade: amigos podem jogar Tênis juntos e tudo o que é feito dentro da quadra não interfere no relacionamento entre ambos fora dela; quando isso ocorre, a atividade é frequentemente considerada "não saudável". 
Tendo em vista que em vários jogos as condições de derrota são sempre mais numerosas que as de vitória e, quanto mais etimado for o objeto, mais difícil será obtê-lo, a garantia de diversas tentativas funciona como fator de equilíbrio. Sendo assim, excetuando-se campeonatos ou outros eventos específicos, é sempre possível recomeçar um jogo ou continuá-lo do mesmo ponto em que se havia falhado (ou por vezes um pouco antes) fazendo uso das "vidas", "continues" ou "checkpoints" disponíveis. No caso do exemplo citado por Juul, em Donkey Kong (Nintendo, 1981) o jogador tem várias chances, pois não só as condições de derrota são muito maiores que as condições de vitória, como também se trata de um jogo desenvolvido para arcade, funcionando, portanto, por meio da compra de fichas. Além de dispendioso, os jogadores poderiam considerar enfadonho um jogo que os obrigasse a sair para comprar fichas a todo momento, indicando que a implementação das "vidas" tinha uma finalidade prática, que, no fim das contas, não interfere diretamente no enredo: cada vez que uma "vida" é consumida, a fase em que o jogador se encontra é reiniciada, ou seja, todo o processo de desviar dos obstáculos para conseguir chegar até a princesa deve ser feito novamente. Narrativamente, não há nenhum tipo de mudança no percurso empreendido pelo herói no enredo, posto que a chance extra reinicia o percurso do zero; é como se, na leitura de um romance, o leitor voltasse as páginas até o início de um capítulo quando ficasse confuso. Portanto, em Donkey Kong, o recurso de várias chances é usado como um marcador de fase para não obrigar o jogador a reiniciar o jogo todo a cada falha; além disso, permite que se jogue por mais tempo antes de ser necessário comprar outra ficha, aumentando o interessante dentro do contexto de um arcade. Não há nada de incoerente no que toca o enredo, pois o sistema de "vidas" não interfere diretamente nas relações entre as personagens ou nos acontecimentos em si, apenas no evento jogo enquanto atividade social - postular uma versão de Donkey Kong sem esse sistema seria como exigir que alguém lesse um romance em voz alta e, a cada erro de leitura, o livro fosse fechado, obrigando o leitor a pagar uma taxa para recomeçar a partir da primeira página. 
Problemas interpretativos de elementos estruturais de jogo não são incomuns quando o olhar crítico é baseado em conceitos construídos a partir da reflexão acerca de objetos que, apesar de apresentarem alguns pontos em comum com os jogos digitais, são bastante distintos. É o caso de Stallabrass (1996), quando faz uma apreensão crítica não de um jogo em particular, mas do fenômeno como um todo. O autor, baseando-se largamente em Adorno e em Benjamin, argumenta que um dos fatores mais importantes do jogo encontra-se na sua forte relação estrutural com a lógica mercantil liberal e aponta, dentre outros fatores, como as diversas chances dadas ao jogador e os gráficos do jogo - considerados pelo autor um "verniz" que esconde a estrutura indiferenciada dos códigos produzidos em massa - podem ser lidos como alegorias do modelo capitalista mercantil. Nas palavras do autor:

\begin{abstract}
Digitised combat has established a fiction of multiple lives and 'hit-points', which measure the degree of injury a character can sustain. This lack of consequence is indicated by the disappearance of bodies and other debris soon after they fall or even in the act of their annihilation so that the arcade machine-gunner may see hundreds of zombies fall before the muzzle, but not a corpse will be left in sight when the smoke clears. Or, if they do remain visible, as in Doom, no matter where they were shot or how they fell, all the corpses of a particular monster always look exactly the same. In Operation Wolf, and its numerous clones, the player guns down countless foes (and innocents if careless) slowly sustaining ever greater damage from enemy bullets and grenades, as if this were mere work, sapping energy. When the player finally succumbs, he finds himself in jail! ... with the option to continue for another coin. In adventure games characters at death's door can be completely revived by a little food and a good night's sleep. Anyone who has been attacked or injured knows that this is not how it is. Yet the games have to pursue this fiction, largely because of the limitations of the medium and its marketing. In the arcade game there is no time for suspense, and it is unprofitable to kill off the player with a single bullet. Enemies must advance and die in hordes, but for the player nothing can be irrevocable. (p. 94)
\end{abstract}

Para o autor, tudo é feito para alargar o tempo dedicado à atividade pelo jogador, que, utopicamente, consegue avançar mesmo com todos os indícios de impossibilidade - é possível, no jogo, realizar o ideal do self-made man. No entanto, a ironia, para Stallabrass, reside no fato de que não é necessariamente o jogador que conquista a máquina:

The player's subordination of the game is achieved through the game's conquest of the player. Computer games perform simulated acts of 
reification in which slices of immaterial code act as living beings but are arranged and treated as objects. The brutal simplification of these digital figures is a register of objectification. (p. 97)

Embora essa leitura possa ser interessante enquanto alegoria, é importante ter em mente que a codificação é parte integrante de um computador que, para (re)produzir qualquer tipo de informação, faz uso de cadeias numéricas binárias. Tanto a textura, quanto a base de polígonos, o texto e os diversos elementos sonoros são processados pelo computador por meio de códigos, que não podem ser entendidos, portanto, como uma forma de esconder algo imaterial: trata-se da produção de uma obra ficcional, e, no caso dos jogos, códigos de programação são tão imateriais quanto palavras descrevendo uma cena ou uma camada de tinta que representa um lábio em um retrato do século XVIII - são os blocos de construção utilizados, não um meio de esconder ou falsificar o que quer que seja. O desaparecimento de elementos e a indiferenciação dos "cadáveres" observados por Stallabrass decorrem da limitação tecnológica da época em que o texto foi escrito: tendo de ser processados em tempo real, elementos que não têm mais utilidade na mecânica do jogo - destroços, inimigos eliminados, etc. - são removidos ou transformados em texturas de baixa taxa de polígonos para que a memória da máquina seja utilizada em outros processos.

Quanto aos elementos que facilitam a vida do jogador, como já foi dito neste artigo e como é apontado por Stallabrass, há uma relação evidente entre eles e a questão das consequências da atividade lúdica: esta não pode ser estruturada de modo tão sério ou "realista" a ponto de eliminar o componente de diversão que existe em sua base. Um jogo difícil demais ou que tenha consequências irreversíveis para cada ação feita pelo jogador pode facilmente ser considerado desinteressante e, portanto, abandonado. Isso, no entanto, não representa um problema, já que diversas formas de arte criaram artifícios formais para lidar com a questão mercantil, desde os finais impactantes de capítulo nos romances folhetinescos - que serão discutidos um pouco mais adiante neste artigo - até os cartazes, trailers e sinopses de filmes que são cuidadosamente elaborados a fim de atrair o maior número possível de espectadores. Não levar em conta esses 
aspectos ou considerá-los como degradantes por seu materialismo é ignorar os meios de produção e recepção como parte da arte e do modo como ela se relaciona com a vida, tratá-la como se fosse etérea e fora do conjunto de práticas socioculturais existentes na história humana.

As incoerências, deficiências e falhas apontadas, portanto, residem não no objeto, mas na interpretação feita com base em conceitos não pertinentes alheios às questões específicas suscitadas pelos jogos digitais enquanto meio expressivo autônomo, cujas bases de produção de sentido são bastante diversas das de outras formas de arte. Não se trata, contudo, de falta de seriedade por parte dos críticos citados, mas de uma carência de literatura específica a respeito do tema, de uma lacuna que tanto Stallabrass quanto Juul diminuíram consideravelmente ao publicar suas reflexões e teorias.

O desafio para os pesquisadores é entender como os elementos específicos de um jogo digital estão relacionados ao enredo para que, assim, seja possível considerar o objeto como narrativa-em-jogo em vez de encará-lo como uma narrativa-apesar-do-jogo. Havendo uma base para a forma expressiva (a relação de um conteúdo com uma estrutura de conflito participativo), a questão da produção e da recepção pode ser encarada em termos de gênero, tornando o assunto ainda mais complexo, pois, em grande parte dos casos, a própria noção de gênero se baseia na repetição de modelos não só no processo criativo, mas na recepção em modo geral: reconhecemos algo como jogo porque estivemos cercados de jogos a vida toda e, quando algo foge do esperado, há um período de estranhamento e adaptação. Para melhor entender essa problemática, serão utilizadas a teoria semiótica de linha francesa e também as considerações de Achcar (1994) a respeito das práticas de composição e recepção da poesia clássica. O objetivo é tentar entender de que modo as convenções genéricas operam em nosso modo de produzir e receber os diversos textos com os quais entramos em contato diariamente. 


\section{A questão genérica e as relações entre expressão e conteúdo}

De acordo com Greimas e Fontanille (1991, p. 18-20), a produção de sentido é baseada em um corpo, o qual, antes de ser capaz de discretizar o mundo em categorias inteligíveis, o sente e, por sua sensibilização, sedia $o$ ato semiótico. Fontanille (2011, p. 1-8) continua a reflexão acerca da sensibilização e retoma o modelo de Hjelmslev e coloca o corpo como operador da função semiótica ao unir o estímulo externo (o plano de expressão) ao fundo cultural interno (o plano de conteúdo), argumentando, portanto, que a junção dos dois planos da linguagem não pode ser feita sem nenhum enviesamento, tendo em vista que nossa leitura acerca do mundo é feita a partir do modo como o interoceptivo molda o modo de ver o exteroceptivo (p. 11-3) - trata-se do domínio do proprioceptivo, do qual já falavam Greimas e Fontanille (1991, p. 18).

Levando-se em conta esse modelo, é possível pensar no ato criativo, enquanto processo semiótico, nos seguintes termos: para o romancista, a página em branco representa não uma possibilidade infinita de sentido, mas uma limitação baseada no fundo cultural que dita não só o que pode ser feito a partir dela, mas também como isso pode ser feito - a página pode estar em branco, mas não é vazia. $\mathrm{A}$ respeito desse assunto parece interessante a consideração feita por Achcar (1994):

\footnotetext{
Essa ação histórica [da tradição poética] se exerce a todo momento, com ou sem a consciência dos autores e dos leitores. Quando vemos impressas numa página linhas de tamanho irregular, e pensamos: versos, e portanto nos dispomos a um tipo de leitura diferente daquele que demandaria um texto de prosa - nesse momento, anterior a qualquer sentido desenhado pelas palavras do poema, já temos um "sentido" prévio, um registro que nos é fornecido pela tradição literária. (p. 17)
}

Apesar de Achcar lidar com poesia clássica, seu argumento pode ser ampliado a toda produção literária: a divisão em capítulos era uma exigência imposta aos romances folhetinescos pelas próprias condições específicas de produção e circulação dos textos literários no século XIX; o uso de desfechos impactantes ou misteriosos no final de cada capítulo servia à necessidade de manter o leitor 
curioso e atento à trama para que evidentemente continuasse a acompanhar a obra. Nos dias atuais, os livros não são mais vendidos "aos pedaços", mas a organização em capítulos segue moldes parecidos e, portanto, o conteúdo também é estruturado de modo similar: há um estilo romanesco de escrever e os leitores esperam que os romances sejam escritos de uma determinada maneira e não de outra - como bem demonstra o sucesso comercial de romances como $O$ Código Da Vinci, de Dan Brown. Isso é o que Achcar denomina, a partir do termo "composição genérica" de Francis Cairns, "codificação da prática intertextual", definida como "uma forma particular de 'arte alusiva': um poema toma do repertório tradicional uma série de lugares-comuns e, juntamente, a maneira de organizá-los, derivando daí sua pertinência genérica." (p. 18) O gênero, sobretudo na prática letrada anterior ao século XIX, é a chave de leitura principal para qualquer texto.

Isso não significa, no entanto, que os textos sejam congelados e consistam meramente em uma eterna repetição. Lugares-comuns podem ser trabalhados de diversas maneiras e, em muitos casos, a originalidade se constrói a partir de um uso inusitado de um lugar-comum, como bem aponta Achcar:

\footnotetext{
Assim, quando Horácio diz carpe diem, em qualquer das diversas maneiras por que o faz, ele está não só dizendo o que diz, mas está tambpem aludindo a um paradigma de outras expressões do mesmo lugar-comum da poesia simposial [...] seu poema se inscreve num gênero, o que significa dizer que o leitor familiarizado tem diante de si a expectativa de um conjunto de outros tópoi [lugares-comuns] do paradigma genérico, organizados segundo esquemas conhecidos. A novidade e a propriedade com que esses lugares-comuns são expressos, a habilidade com que são correlacionados, ou a originalidade com que são exploradas novas possibilidades de organização - nisso consiste parte essencial dessa arte de que Horácio foi mestre exímio. (Ibidem)
}

Um exemplo de uso engenhoso de lugares-comuns de diferentes tradições é dado por Achcar (p. 17-18): no poema 8 de Catulo, além de obedecer às regras de composição genérica próprias ao gênero renuntiatio amoris ("renúncia amorosa", numa tradução livre), o poeta faz uso do coliambo - um metro "tradicionalmente usado na comédia e na sátira, pelo efeito humorístico causado pela inversão do pé final” (p. 17), o qual confere ao poema um tom cômico, 
satírico. Outro exemplo, no campo literário, de uso da forma para criar efeitos de sentido inusitados é o romance Drácula, de Bram Stoker. Nele, a divisão por capítulos é apresentada no plano geral do romance sob a máscara de uma reunião de documentos diversos: um trecho de diário de Jonathan Harker é sucedido por uma carta de Mina a Lucy ou um recorte de jornal; essa organização exige que o leitor desenhe por si o fio narrativo a partir de dados variados, contrastando pontos de vista e modos de narrar a experiência de cada personagem, simulando uma investigação policial ou pesquisa histórica. A descontinuidade da leitura de um romance é, em Drácula, transformada em elemento estético, pois, de certa forma, coloca o leitor dentro do plano ficcional, convidando-o a fazer parte da trama como detetive/historiador.

Do exemplo de Catulo e de Bram Stoker, é importante reter a relação entre ritmo e divisão gráfica em capítulos (dados da expressão) e sátira e simulação de uma pesquisa (dados do conteúdo); considerando as reflexões da teoria semiótica francesa, poderemos classificar essa relação como semissimbólica. Semissimbolismo, tal como se encontra definido em Pietroforte (2012, p. 7-10), é a relação arbitrária entre traços da forma dos diferentes planos da linguagem; no caso do poema de Catulo, o traço "satírico" ou "cômico", no plano do conteúdo, se relaciona diretamente com o traço "invertido", no plano da expressão, fazendo supor que um ritmo "regular" (ou "normal") seria associado a um conteúdo "sério" ou até mesmo "trágico". É razoável considerar que o uso contínuo de uma relação semissimbólica a cristaliza e, naturalmente, a torna parte de um gênero específico ou é adotada amplamente nas mais diversas composições - o que tornaria essa relação simbólica, talvez. De qualquer maneira, o que aqui interessa é justamente o fato de que um dado expressivo qualquer - no caso, a inversão rítmica - fornece ao leitor habituado uma "dica", uma espécie de "chave de leitura" daquele texto em particular. Retomando o exemplo do romance, poder-se-ia argumentar que um leitor assíduo de romances saberia prever quando um capítulo está próximo do fim tendo como base apenas o andamento da narrativa uma cena de perseguição desenfreada seria um encerramento considerado adequado. Mudando o tipo de texto e tomando como caso de estudo uma 
produção operística, vê-se como é senso comum atribuir timbres mais graves de VOz (contralto, barítono) aos antagonistas e coadjuvantes, enquanto as personagens principais da trama seriam representados por atores de voz mais aguda (soprano, tenor), o que tornaria perfeitamente possível o reconhecimento de um vilão antes mesmo de o enredo revelá-lo como tal. Esse tipo de dado, que pode não aparecer textualmente explícito e que não é necessariamente veiculado pela organização do enredo, será, aqui, referido pelo conceito de informação narrativa.

Como demonstrado acima, qualquer elemento do texto pode conter informação narrativa. É o caso da maquiagem utilizada em alguns atores no filme Star Trek (Paramount, 2009): o enredo é centrado na instituição ficcional denominada Frota Estelar, responsável por explorar a galáxia para estudar novas formas de vida, estabelecer relações com diferentes povos e demais tarefas do gênero. Alguns tipos de alienígenas são nomeados e têm papel importante no desenrolar da trama (os Vulcanos e os Romulanos, por exemplo), mas há diversos outros não nomeados dos quais o espectador tem conhecimento por comparação de tons de pele (verdes, azuis) ou traços físicos (chifres, formatos de crânio) de personagens que destoam daqueles mais comuns aos humanos representados no filme. Isso amplia consideravelmente o universo ficcional de Star Trek, pois permite ao espectador pressupor vários eventos não expostos, os quais teriam como foco 0 estabelecimento de relações entre os diversos povos apresentados visualmente. Nesse sentido, a maquiagem utilizada é um dos elementos de composição que ampliam a quantidade de informação narrativa veiculada pelo filme.

No entanto, o enredo não contempla (ou não é capaz de contemplar) toda a informação veiculada pelos diversos elementos que compõem o filme, o que gera a sensação de incompletude atribuída por Juul a alguns universos ficcionais dos jogos digitais. Essa sensação de que há mais além do que é narrado deriva do fato de o enredo não saturar a quantidade de informação anunciada pelos demais elementos da obra. O uso do termo "saturação" não tem aqui sentido pejorativo; refere-se ao sentido bastante comum em sintaxe, que postula a 
saturação de um verbo quando todas as posições de argumento exigidas por ele estão preenchidas. Um exemplo rápido com o verbo "pôr":

\author{
(1) Eu pus \\ (2) Eu pus uma camiseta \\ (3) Eu pus o vaso de flores \\ (4) Eu pus o vaso de flores em cima da mesa
}

Em (1) a frase encontra-se incompleta, pois falta o complemento direto, presente em (2) e (3). Aquela se encontra saturada, já que o verbo "por" torna-se sinônimo de "vestir" quando o complemento é um substantivo com o traço semântico de "vestimenta", enquanto esta ainda parece incompleta, atingindo a saturação em (4), quando adicionamos um complemento locativo. Trata-se, portanto, um conceito totalmente dependente do discurso - cada situação de enunciação vai delimitar um nível de saturação diferente. Neste trabalho, o conceito será considerado da seguinte maneira: o enredo contempla quantidade $X$ de informação, enquanto o aparato visual do filme apresenta $X+n$ elementos, indicando que o plano da expressão não é isonômico em relação ao plano do conteúdo. Os dados expressivos visuais não representam necessariamente figurativizações discursivas baseadas em estruturas narrativas do percurso principal do filme. Como nossa cognição é, segundo a semiótica francesa, baseada em um percurso que parte de categorias abstratas e as molda em estruturas narrativas, toda informação não formulada explicitamente em forma de enredo (i.e., não saturada) é, por nós, colocada em um percurso outro, que concorre com o principal apresentado pelo texto. Dito de outro modo, nossa cognição "inventa histórias" para tudo o que não é contemplado pelo enredo quando não há saturação, expandindo, assim, o universo ficcional. Esses elementos diversos funcionam como gatilhos que causam uma espécie de "reação em cadeia" cognitiva produtora ela mesma de histórias dentro de histórias, gerando a sensação de incompletude.

Como os elementos responsáveis por isso não são compostos de modo aleatório, mas ordenado, trata-se, evidentemente, de uma estética que é engenhosamente utilizada em diversos gêneros. A seguinte reflexão torna-se, neste contexto, 
pertinente: as histórias não contadas em filmes como O Diabo veste Prada ou Diário de uma Paixão causam a mesma inquietação que as de filmes como Star Wars ou livros como Harry Potter e a Pedra Filosofal? Talvez os espectadores, reconhecendo nos primeiros exemplos citados um universo ficcional que, supostamente, se confunde com o nosso, considerem os enredos desses filmes como saturados, enquanto trabalhos de ficção científica ou fantasia, por se afastarem consideravelmente do que é conhecido, tenham como objetivo a não saturação, responsável, ironicamente, por tornar esses universos mais reais e palpáveis. Criar a sensação de que se mostra apenas parte de um todo faz com que esse "todo" pareça orgânico, pulsante e que exista independente do objeto ficcional contemplado.

Outro exemplo de como a sensação de saturação não está necessariamente ligada ao enredo é o das telenovelas. Exibidas diariamente ao longo de meses, dificilmente o público consegue acompanhar cada capítulo ou até mesmo lembrar de detalhes de todos eles, e muitas vezes começa-se a acompanhar a obra quando vários já foram exibidos. Ainda assim é possível sentir-se saturado pelas telenovelas, posto que há várias repetições ao longo da trama, flashbacks e outros recursos que permitem ao espectador "ligar os pontos" mesmo quando se deixou de assistir por alguns dias, situação que, evidentemente, é levada em conta pelos autores na elaboração de cada novo capítulo; além desses recursos, o próprio gênero, que acolhe tramas bastante parecidas, contribui para que a sensação de saturação independa da recepção completa do enredo. De modo similar, mesmo que um desfecho seja dado a todos os eventos, os espectadores podem julgar que as coisas estão "mal explicadas" devido a informações narrativas veiculadas por elementos diversos, causando o efeito oposto àquele observado em Star Trek, em que a falta de saturação é algo positivo.

Cada gênero, portanto, tem pontos de saturação diferentes e irá trabalhar de maneiras as mais diversas para tirar o máximo de proveito da expectativa do enunciatário. Atenta a essa questão, Murray (1997), em seu estudo sobre a estética do ciberespaço, fala a respeito de como os produtos narrativos digitais, 
que não têm, necessariamente, uma linha de enredo, se relacionam com o conceito de saturação, que é essencial em formas expressivas alineares ou de final aberto, como é o caso de alguns jogos digitais. As considerações a respeito dos limites do cyberespaço e de como é possível criar narrativas sem um enredo claramente delineado serão o tema da próxima seção.

\section{Alinearidade, saturação e o modelo narrativo aberto}

De acordo com Murray (1997), a estética do ambiente digital é baseada em três pontos básicos, que, se não são exclusivos desse meio, encontram-se ali combinados e com maior intensidade. São eles a sensação de imersão, o poder de agência e a capacidade de transformação. O primeiro, definido por ela como "the sensation of being surrounded by a completely other reality, as different as water is from air, that takes over all of our attention, our whole perceptual apparatus" (p. 98), diz respeito à sensação criada pela ficção em geral, a suspensão da realidade cotidiana por outra, seja ela elaborada por meio de palavras ou imagens; a diferença presente no digital é a estruturação de um ambiente simulado, no qual é possível navegar, transformando a imersão em participação: "in a participatory medium, immersion implies learning to swim, to do the things that the new environment makes possible." (p. 99) Isso evidentemente está ligado ao segundo ponto: "Agency is the satisfying power to take meaningful action and see the results of our decisions and choices" (p. 126), que não se confunde com o conceito de "interatividade":

\footnotetext{
Because of the vague and pervasive use of the term interactivity, the pleasure of agency in electronic environments is often confused with the mere ability to move a joystick or click on a mouse. But activity alone is not agency. For instance, in a tabletop game of chance, players may be kept very busy spinning dials, moving game pieces, and exchanging Money, but they may not have any true agency. The players'actions have effect, but the actions are not chosen and the effects are not related to the players' intentions. Although hamemakers sometimes mistakenly focus on the number of interactions per minute, this number is a poor indicator of the pleasure of agency afforded by a game. Some games, like chess, can have relatively few or infrequente actions but a high degree of agency, since the actions are highly autonomous, selected from a large range of possible choices, and wholly determine the course of the game. (p. 128)
} 
A diferença entre a ação e a sensação de que a ação é significativa é vital para entender o que se passa em um jogo digital em contraste com alguma obra de hipermídia que possa parecê-lo visualmente, mas não apresente uma estrutura de conflito e não possibilite a sensação de agência, a qual Murray liga ao jogo:

\footnotetext{
Agency, then, goes beyond both participation and activity. As an aesthetic pleasure, as an experience to be savored for its own sake, it is offered to a limited degree in traditional art forms but is more commonly available in the structured activities we call games. (pp. 128-129)
}

Um caso bastante famoso é o de Dear Esther (The Chinese Room, 2012), obra de hipermídia com modo de navegação em primeira pessoa por ambientes tridimensionais, mas que não possibilita agência e não apresenta estrutura de conflito. O usuário do sistema move-se por cenários desabitados sem que haja qualquer tipo de comando para abrir uma porta ou livrar-se de um obstáculo; não há nenhum enigma a resolver ou desafio que precise ser feito para prosseguir, e os únicos eventos são pedaços de texto mostrados na tela e narrados por uma voz masculina que não se sabe a quem pertence. A estrutura de Dear Esther é muito mais próxima de uma obra de literatura hipermidiática, como Afternoon, a story (Michael Joyce/Eastgate Systems, 1990) - não considerada um jogo - do que de algo como Candy Crush Saga (King, 2012) - um dos jogos mais populares da atualidade. Em Afternoon, a story, o leitor vê-se obrigado a prosseguir na leitura do texto clicando em palavras não marcadas no texto; cada clique dará origem a um novo trecho e assim por diante, podendo chegar-se a um beco sem saída. Cada usuário desse sistema vai chegar a um texto diferente sem que haja um fim claro ou uma linha de enredo a seguir. A diferença entre essa estruturação e a de Dear Esther reside no modo de apresentação, muito mais visual e imersivo neste do que naquele, baseado puramente em navegação textual por meio de hiperlinks ocultos. A confusão ocorre porque, como Murray aponta, essas estruturas de navegação no ciberespaço são bastante ligadas aos jogos e, portanto, são reconhecidas como tal; o desconforto causado por Dear Esther reside justamente no fato de a estrutura da obra não corresponder ao que é anunciado por sua expressão visual, bastante similar a de vários jogos de exploração existentes no mercado. 
Prosseguindo com a teoria de Murray, o último aspecto, o de transformação, é derivado do aspecto procedural que se encontra na base dos computadores:

The computer captures processes, and it therefore is always suggesting processes to us even when it is just displaying information. Anything we see in digital format - words, numbers, images, moving pictures becomes more plastic, more inviting of change. (p. 154)

Esse novo modo de lidar com a informação, mais próximo do caleidoscópio que do mosaico (p. 156-7), cria modos diversos de apresentação de narrativas, nos quais se deve atuar e não meramente observar, privilegiando a multiplicidade de pontos de vista e caminhos em contraste com a linearidade do modo tradicional de narrar, havendo, em última instância, a recusa de um final: "Because of its ability to both offer and withhold, the computer is a seductive medium in which much of the pleasure lies in the sustained engagement, the refusal of clímax." ( $p$. 173-4) De acordo com ela, essa questão é explícita em Afternoon, a story, que deixa a decisão de fim para o leitor: o encerramento é criado de modo diferente para cada um quando se chega a um ponto em que a inquietação gerada pelo enigma ou pela dissonância interna desaparece (p. 174). Nas palavras da autora:

\begin{abstract}
In other words, electronic closure occurs when a work's structure, though not its plot, is understood. This closure involves a cognitive activity at one remove from the usual pleasures of hearing a story. The story itself has not resolved. It is not judged as consistente or satisfying. Instead, the map of the story inside the head of the reader has become clear. Such a map does not necessarily feel inevitable or appropriate, the way the solution to a puzzle does. It may not be beautiful or shapely in any way. There is no emotional release or perception of fittingness, just a sense of going from the unknown to the known. This is very different from and far less pleasurable than our more traditional expectations of closure, as arising from the plot of the story and marking the end point of an action. (Ibidem)
\end{abstract}

$\mathrm{Na}$ leitura aqui proposta, a obtenção de encerramento por meio do entendimento equivale à saturação obtida pelo preenchimento das lacunas com uma estrutura narrativa: os mais diversos dados sensoriais, que veiculam informação narrativa, são ligados pelo leitor com base na relação discursiva entre a competência pré- 
existente ao contato e os estímulos do objeto, e, assim, o texto atinge a saturação, criando a sensação de encerramento proposta por Murray.

A noção de que a estrutura de nossa cognição está baseada em uma narrativização de conceitos abstratos não é exclusiva da semiótica francesa; Ricoeur (2006, pp. 105-138) determina que um dos pontos definidores da identidade de um sujeito é justamente a elaboração de uma progressão baseada, dentre outros aspectos, na memória e na promessa: o sujeito que foi deve ser reconhecido naquele que ainda não é, mas se encontra- em devir. Essa progressão não pode ser entendida senão por uma conexão causal (ou por algo que se assemelhe a ela), demonstrando que a narratividade, que pode, inclusive, ser entendida como a capacidade de narrar(-se), é fundamental para o reconhecimento cognitivo tanto dos outros como de si mesmo. Fontanille (2011, p. 12-3) retoma o modelo de Ricoeur, em sua discussão sobre o conceito de corpo e sua relação com o sentido, ao postular o sujeito como operador da função semiótica hjelmsleviana de união de um plano de expressão a um plano de conteúdo - ideia já desenvolvida em Sémiotique des Passions (1991) em coautoria com Greimas. O plano do conteúdo, por sua vez, pode ser analisado em um percurso estruturado em níveis interdependentes e correlacionados, partindose de uma estrutura fundamental abstrata até uma superfície discursivizada, cujo intermédio é preenchido por um esqueleto narrativo fundamentado em relações lógicas de pressuposição. Essa base de sentido narrativa é basilar para a compreensão da incompletude enquanto estética e parece ser reconhecida até mesmo por Juul (2005, cap. 4), quando este afirma que as lacunas do universo ficcional serão preenchidas por nosso conhecimento prévio acerca do mundo e do gênero a que o objeto pertence - o que também podemos relacionar à ideia de composição genérica presente em Achcar (1994).

Nessa chave de leitura, a análise de Murray (1997) poderia ser entendida da seguinte forma: os mais diversos elementos expressivos presentes no ambiente digital, todos eles portadores de algum tipo de informação narrativa, seriam relacionados de maneiras diferentes a depender do sujeito-base da enunciação - 
o catalisador de sentido, por assim dizer. A compreensão da estrutura necessária para a saturação é não só relativa à forma da expressão com a qual se tem contato - e que, previamente à enunciação, poderia ser considerada invariável, mas também à forma de conteúdo criada em ato a partir dos dados narrativosensoriais latentes e do fundo cultural depositado na memória do sujeito-base; essa relação singular não depende exclusivamente, como dissemos, de uma estruturação de enredo que muitas vezes parece faltar a esses produtos, demonstrando que a linearidade e a finitude narrativas de um texto não são o único meio de produção de sentido de narratividade possível. Há, no entanto, um ponto na apreciação de Murray bastante discutível: a autora afirma que a sensação de encerramento por saturação é menos prazerosa que aquela suscitada por narrativas convencionais; ora, estando a produção de sentido ancorada em um corpo sensível e sendo qualquer conteúdo patêmico derivado de tensões e aspectualizações presentes na base do percurso - antes mesmo de qualquer discretização de categorias semânticas básicas fundamentais, ou seja, previamente a qualquer possibilidade de narrativização, não é possível, em absoluto, associar um tipo de sensação de prazer qualquer que seja a uma de organização narrativa específica ou de organização de plano de expressão, e cada corpo-sujeito responderá a sua própria maneira às mais diferentes relações discursivas entre texto e corpo sensível no processo de enunciação. Sendo assim, não se trata aqui de considerar o tipo de narratividade próprio ao meio digital como superior ou mais elaborado que o modo convencional, mas de estabelecer quais são suas especificidades sem tentar "bater o martelo" a respeito do resultado de sentido que será produzido em um evento impossível de ser reproduzido ou repetido.

Evidentemente, o modelo de narrativa aberta e alinear, cujo encerramento se baseia na saturação, não pode ser considerado como base de todo e qualquer jogo digital. Como aponta Juul (2005, cap. 3), há alguns jogos em que o jogador caminha por estágios bem delineados, com fim definido, e avança pelo enredo ao resolver enigmas ou executar combinações bastante claras, com apenas uma solução possível, como é o caso de God of War (SCE Studios Santa 
Monica/Sony, 2005) ou Final Fantasy XIII (Square-Enix, 2010). São os chamados jogos de progressão, que se opõem, segundo ele, aos jogos de emergência, em que não há uma única solução possível e o desenrolar depende da combinação de elementos programados de formas variadas, como Kirby's Avalanche (HAL Laboratory/Nintendo, 1995) ou Street Fighter (Capcom, 1987), cujo desenvolvimento de enredo é muitas vezes apenas veiculado por texto ou vídeo sem relação direta com a mecânica do jogo (ou então é inexistente).

Cremos que um modelo de jogo primariamente progressivo acolha mais confortavelmente narrativas lineares, enquanto o modo alinear descrito por Murray parece relacionar-se melhor com jogos que salientem seu aspecto emergente. Apesar disso, a própria estrutura básica de um jogo - a qual, como já foi apontado acima, exige que haja um resultado quantificável e possibilidade de derrota, o que exige alguma progressão - torna bastante complexa não só a implementação da alinearidade como também a transposição de conteúdos introspectivos, contemplativos ou passionais em forma de jogo: é preciso estruturar o estático em dinâmico e o contemplativo em uma ação participativa, sendo que a falta de habilidade na execução precisa resultar em derrota. Em suma, o desafio, assim como nas narrativas alineares do ciberespaço, é fazer com que o conteúdo seja transposto em procedimentos para que o jogador sinta o conteúdo enquanto joga: não se trata puramente de uma experiência inteligível, é preciso que, em seu fazer, o conteúdo ecoe na forma.

Resta, agora, averiguar como a alinearidade do ciberespaço, que será associada à estética da incompletude mencionada previamente neste artigo, pode ser o fundamento da produção de sentido em alguns jogos. Para além do que está presente nas formas do cinema e da TV, certos títulos tentam postergar a sensação de encerramento ao introduzir pequenos desafios ou atividades dentro de um frame narrativo ampliado, um universo em que, aparentemente, é possível agir livremente e desenvolver-se de diversas maneiras; é esse o caso do RPG (Role Playing Game) The Elder Scrolls V: Skyrim (Bethesda, 2012) e do 
MMORPG (Massive Multiplayer Online RPG) Final Fantasy XIV: A Realm Reborn (Square-Enix, 2013), que serão brevemente analisados na próxima seção.

\section{A ampliação do narrativo por meio da incompletude}

Antes de analisar os dois títulos mencionados acima, é preciso retomar a definição de jogo e discuti-la sob a luz do seguinte problema: obras que não têm um fim claro ou que permitem a busca por objetivos diversos e não por um único objeto de valor desejável pelos demais jogadores (em potencial) podem ser chamados de jogos? Essa discussão é trabalhada por Juul (2005, cap. 2), que classificou títulos desse tipo como casos de limiar, pois, apesar de haver estruturas de conflito diversas dentro de um frame maior, eles não apresentariam obrigatoriedade na busca por nenhum objetivo em particular, o que anularia 0 princípio competitivo de um jogo. Apesar de bastante coerente, sobretudo quando diz respeito aos RPGs não digitais, regidos por um mestre que elabora situações narrativas umas após as outras, sem uma finalidade clara, no caso digital, devido à sua estrutura pré-programada, parece tratar-se de algo similar aos sistemas de jogo descritos por Salen e Zimmerman (2004).

Um sistema de jogo é um tipo de estrutura que, apesar de não corresponder per se a um jogo, permite que vários deles sejam jogados. Um exemplo bastante conhecido é o do baralho: o sistema de cartas criado muito tempo atrás é usado até os dias atuais para jogar de diferentes modos. No caso dos jogos digitais abertos, apesar de não haver, na maioria dos casos, possibilidade de reprogramação do sistema por parte dos jogadores, ainda assim vê-se que, inseridos no frame, existem diversas modalidades de jogo diferentes entre si. Pensando em The Elder Scrolls V: Skyrim, é possível: 1) seguir as diversas linhas de enredo apresentadas no jogo; 2) superar os desafios registrados textualmente no menu; 3) evoluir as habilidades de criação de armas e armaduras, ignorando completamente o item 1; 4) buscar melhorias para a casa obtida em determinado ponto da linha de enredo "principal"; e assim por diante. Em Final Fantasy XIV: A Realm Reborn, além de todos os elementos citados para The Elder Scrolls $V$ : 
Skyrim, por se tratar de um MMORPG, é possível: 1) organizar-se em uma companhia de jogadores e trabalhar em comunidade; 2) participar de negociações mercantes a partir dos itens criados; 3) participar de combates PvP (Player versus Player). As possibilidades são enormes e todas elas poderiam ser encaradas como um jogo completo em si: para ser bem sucedido enquanto mercador, é preciso superar os desafios das classes de construtores de modo a produzir os melhores produtos e dominar o mercado de itens no jogo, por exemplo. Sendo assim, em um trabalho cujo objeto é o exame da incompletude como efeito de sentido narrativo, parece razoável comparar essa estrutura com a de um sistema de jogos e, a partir disso, deixar de lado alguns dos aspectos apontados por Juul (2005) que classificariam The Elder Scrolls V: Skyrim e Final Fantasy XIV: A Realm Reborn como não jogos ou casos de limiar, por mais pertinentes que possam ser em outros contextos.

A análise por The Elder Scrolls V: Skyrim será feita, portanto, de acordo com essa perspectiva mais ampla em relação às considerações de Juul. Trata-se, como já dito, de um jogo aberto de gênero RPG. Por "jogo aberto" entende-se um tipo de estrutura organizada em torno de um frame - a província de Skyrim, no caso pelo qual o jogador pode transitar (quase) livremente desde o início do jogo. De fato, após a cena de abertura inicial, em que se escolhe a raça, o gênero, a aparência e o nome da personagem, e a fuga do primeiro vilarejo, o jogador pode ir para onde quiser, aceitando quests aqui e ali ou simplesmente praticar qualquer tipo de ação para evoluir os atributos - que vão desde potência mágica e manejo de arcos até furtividade e uso de armaduras pesadas. Não há uma linha de desafios que obrigue o jogador a seguir este ou aquele caminho, o que elimina qualquer possibilidade de linearidade de enredo e abre espaço para um tipo diferente de contar histórias: cada cidade vai abrigar diferentes personagens não jogáveis com as quais o jogador pode se relacionar, ouvindo o que elas têm a dizer ou então aceitando suas quests - cada uma delas funcionando como um nó em uma rede que é acessado livremente e permite a entrada em algum conflito a ser resolvido, transmitindo informação narrativa por meio de uma vivência do mundo; o jogador passa boa parte do tempo realizando tarefas como caçar 
bandidos, derrotar algum monstro ou levar encomendas, todas elas figurativizadas como um evento cotidiano dentro da organização social da província em que se passa o jogo. Em cada cidade, as figurativizações serão diferentes, permitindo um contraste cultural interessante, apesar da repetição. Além disso, há missões mais elaboradas, que são encadeadas em linhas de enredo, muitas vezes envolvendo a exploração de alguma ruína ou a ajuda em uma revolução, ampliando consideravelmente a vivência dentro do frame.

Embora seja possível esgotar as linhas narrativas jogando-se diversas vezes, há um algoritmo em The Elder Scrolls $V$ : Skyrim que gera quests aleatoriamente (embora todas sejam similares). No entanto, é razoável supor que o jogador atinja a saturação antes de visualizar boa parte do conteúdo do jogo, tanto o fixo quanto o gerado pelo algoritmo. Baseados em uma estrutura repetitiva de temas e figuras, no que se refere ao plano do conteúdo, e de mecânica de jogo e estímulos sensoriais, no plano da expressão, os diferentes objetivos e modalidades não precisam ser completos individualmente para que se passe do desconhecido ao conhecido, como menciona Murray (1997). Mesmo jogos cuja linha de enredo é única tendem a ser abandonados após algumas poucas partidas, pois a experiência de jogo em títulos de mesmo gênero pode ser muito parecida e, como se trata de uma narrativa baseada em uma vivência, isso muitas vezes supera qualquer novidade figurativa ou temática que o enredo possa apresentar.

O mesmo ocorre em Final Fantasy XIV: A Realm Reborn: o jogador cria livremente sua personagem e pode seguir as mais diversas linhas de quests de modo a vivenciar os problemas de um continente que tenta se reerguer após uma catástrofe natural enquanto é ameaçado por uma nação imperialista. A diferença básica entre o jogo anterior e este é seu caráter online: Final Fantasy XIV: A Realm Reborn permite experiências com múltiplos jogadores e, em algumas quests, isso é exigido. Portanto, além do acesso aos nós de informação, é possível intercambiar experiências enquanto se joga, aumentando consideravelmente a sensação de que há um universo ficcional ativo e pulsante 
apesar da ação do jogador. Por fim, MMORPGs são constantemente atualizados pelas empresas, abrindo novas linhas narrativas e incluindo novas possibilidades de evolução para as personagens, constituindo-se como uma obra ficcional em processo e não como algo pronto; para que essas mudanças sejam implementadas coerentemente, há personagens com as quais não se pode interagir e diversos caminhos fechados nos cenários, mas que parecem levar a algum lugar que talvez seja revelado em uma atualização futura, dando origem a novas raças e desafios a completar.

Esse conteúdo latente, denunciado pelas personagens que vagam pelos cenários, pelos caminhos fechados, pelas referências a um passado remoto ou por meio das esperanças depositadas em um futuro, penetra no jogador em sua vivência narrativa e adquire sentido no ato discursivo de jogar, que, como já dito, preenche as lacunas com estruturas narrativas figurativizadas a partir do conhecido sobre 0 gênero, ampliando constantemente o universo ficcional ao lançar alhures os seus limites, mantendo a narrativa sempre em devir, sem qualquer possibilidade de encerramento. A incompletude é transformada em estética quando se coloca no corpo do jogador a narrativa enquanto experiência de uma vida virtual que carrega a promessa do eterno.

\section{Conclusão}

O percurso argumentativo deste artigo teve por objetivo demonstrar como os fundamentos da teoria narrativa, descritos há mais de dois milênios por Aristóteles e posteriormente retomados, em outra chave de leitura, pela semiótica francesa, encontram-se fortemente enraizados em nossa forma de receber e produzir textos, mesmo quando a alinearidade, a impossibilidade de encerramento claro e a composição lacunar formam a base de composição dos textos - elementos que, combinados, formam uma estética da incompletude. Esse novo modo de conceber a arte narrativa muda o foco do produto para o processo: em vez de uma simples característica da ficção, trata-se de um efeito de sentido cuidadosamente fabricado pelos mais diversos autores, os quais não reduzem um 
todo ao apresentarem meramente uma de suas partes, mas possibilitam que se amplie e transcenda, por meio de nossa competência narrativa, aquilo que é captado pelos sentidos. A estrutura da significação se impõe, demonstrando que o sentido não reside puramente no objeto, mas no fenômeno discursivo, na linguagem viva e pulsante, com suas lacunas tanto intrínsecas quanto fabricadas que se tornam plenas no contato entre texto e corpo, no jogo que chamamos de semiose.

\title{
NARRATIVE INCOMPLETENESS AS A MEANING EFFECT IN VIDEO GAMES
}

\begin{abstract}
If we take the term "narrative" in a broad sense, we certainly could not affirm that each and every video game is a narrative. Tetris, for instance, presents blocks that need to be organized in lines if the player wants to get points, and this obviously is not a narrative per se. Donkey Kong, on the other hand, has characters like a man, a gorilla and a princess in a conflict structure that creates a narrative with a beginning and an end. In spite of that, Jesper Juul (2005) considers that kind of fictional universe as incomplete - since we do not know where the princess comes from or how she was captured by the ape - and incoherent - because the main character has many lives available. This particular point of view has many problems since: 1) it implies that a game is a way of portraying a pre-existing universe, for, to be considered incomplete, it must have some degree of completeness beyond the content shown in the game; and 2) uses as means to measure coherence some elements that are alien to the video game genre, such as ones we may apply to our everyday life or the criteria we use to evaluate other art forms. We propose that the elements which Juul links to incompleteness and incoherence form the basis of the video game form itself, and thus can not render it incoherent nor incomplete - the sensation of incompleteness is a particular meaning effect, an artifice created by the link between a particular expressive mean and the narrative content, and a way of amplifying the fictional experience itself. Our argument is mainly based on French Semiotics Theory and on the works of Aristotle, Achcar (1994) and Murray (1997).
\end{abstract}

KEYWORDS: French Semiotics. Narrative Theory. Video Games. Cyberculture.

\section{REFERÊNCIAS}

ACHCAR, F. Lírica e Lugar-Comun: Alguns Temas de Horácio e sua Presença em Português. São Paulo: EDUSP, 1994.

FONTANILLE, J. Corps et Sens. Paris: PUF, 2011.

GREIMAS, A. J.; FONTANILLE, J. Sémiotique des Passions: Des états de choses aux états d'âme. Paris: Seuil, 1991.

HOUAISS, A.; VILLAR, M. S. Dicionário Houaiss da Língua Portuguesa. Rio de Janeiro: Objetiva, 2009. 
JUUL, J. Half-Real: Video Games between Real Rules and Fictional Worlds. Cambridge: The MIT Press, 2005. Formato E-Book.

MURRAY, J. Hamlet in the Holodeck: The Future of Narrative in Cyberspace. Cambridge: The MIT Press, 1997.

PIETROFORTE, A. V. Semiótica Visual: os percursos do olhar. São Paulo: Contexto, 2012.

RICOEUR, P. Percurso do Reconhecimento. São Paulo: Edições Loyola, 2006.

SALEN, K.; ZIMMERMAN, E. Rules of Play: Game Design Fundamentals. Cambridge: The MIT Press, 2004. Formato E-Book.

SOUSA, E. (trad.). Aristóteles. Poética. São Paulo: Abril Cultural, 1973.

STALLABRASS, J. Gargantua: Manufactured Mass Culture. New York: Verso, 1996.

Texto recebido em: 06/06/2014

Texto aceito em: 14/07/2014 